\title{
Medical provision and usage for the 1999 Everest marathon
}

\author{
D G W Buckler, F O’Higgins
}

The Everest marathon is a biannual race run from 5184 m near Everest base camp and finishing in the Sherpa capital of Namche Bazaar at $3446 \mathrm{~m}$. It is recognised as the highest and possibly the toughest marathon race in the world. The runners start at a height at which the atmospheric pressure and inspired oxygen pressure are $50 \%$ of the value at sea level. ${ }^{1}$ It began in 1987 to an outcry from many altitude experts who felt the risks of running at that altitude were unjustifiable. ${ }^{2}$ However, it has proven to be a safe if tough race. There have been no fatalities. On average over the seven marathons, $5-10 \%$ of contestants have been unable to complete the whole race, some completing part of the course. ${ }^{3}$ In 1995 the course was unsafe because of a heavy snowfall, and only a half marathon was run. The previous races have been held in late November after the monsoon season. This year for the first time it was held in April, a warmer time of year. Daytime temperatures were typically around freezing, falling at night to $-10^{\circ} \mathrm{C}$.

The main medical problems facing previous medical teams have been altitude sickness, diarrhoea and vomiting, chest infections, and musculoskeletal disorders, especially anterior knee pains, contusions, and blistering of the feet. ${ }^{4}$ Knowledge of previous problems and the use of drug formularies from previous marathons helped to ensure that the expedition was adequately equipped.

\section{The medical team and equipment}

This isolated route is away from medical access for long parts of the trek, requiring the medical team to be completely self sufficient. The race has potential for life threatening altitude illness and also major trauma, especially in the first 3 miles where the runners pass through the moraine of the ice fall in subzero temperatures.

In order to acclimatise to the hypoxic cold conditions, runners spend 3 weeks trekking to the start line across high passes; this is in line with the internationally agreed rate of ascent to avoid altitude illness. ${ }^{5}$

The medical team this year consisted of 12 people. Nine were doctors: five general practitioners, two of whom had additional qualifications in sports medicine, two anaesthetists, one doctor trained in intensive care, and a surgeon. Six of the doctors had altitude experience. There was also an experienced expedition nurse, an osteopath, and a physiotherapist.
There were three groups trekking; each group needed to be self sufficient as they were out of contact with each other and the outside world. The drugs were split among the three teams and each group had a mixture of skills within the medical team.

Each medical team carried a comprehensive resuscitation kit. This included equipment to be used in the event of cardiac arrest, serious altitude sickness, and trauma. ${ }^{6}$ Equipment included various airway adjuncts, self inflating resuscitation bags, and oxygen, as well as large bore intravenous cannulae and crystalloid fluids. Emergency drugs were also carried, including adrenaline, atropine, and drugs, such as dexamethasone, nifedipine, acetazolamide, and furosemide (frusemide), to treat life threatening altitude sickness. In these hypoxic conditions, general anaesthesia is hazardous and should be avoided, local anaesthetic techniques being preferable. ${ }^{7}$ However, various agents including ketamine were carried in case of an emergency, with the view that total intravenous anaesthesia would be the technique of choice. At this altitude, cerebral and pulmonary oedema are real possibilities, and it is essential that both resuscitation equipment and expertise are available.

\section{Contestants}

The chief medical officer was responsible for reviewing the medical forms of every contestant before departure for Nepal. One applicant was refused permission to take part because of a protein $S$ deficiency, which would necessitate maintenance warfarin monitoring. It was felt that the risks of altitude were too great for him.

Contestants with the following conditions were accepted for the trip:

- previous paroxysm of atrial fibrillation requiring direct current cardioversion;

- insulin dependent diabetes mellitus;

- asthma;

- previous altitude sickness at a height below that of the start line.

The athlete with previous paroxysms of atrial fibrillation shared a tent with a doctor, as it was not known whether the strain of altitude would precipitate a paroxysm, although current evidence about travelling to altitude with heart disease is encouraging ${ }^{5}$; however, there is no information on running at altitude. The diabetic lady was thought to be at risk from the extra strain of altitude coupled with the irregu- 
lar timing of meals which is unavoidable on expeditions. The five athletes with previous altitude sickness were treated with prophylactic acetazolamide from a height of $3446 \mathrm{~m}$; a regimen of acetazolamide $0.125 \mathrm{mg}$ twice a day was used in line with the recommendations of the CIWEC clinic in Katmandu. ${ }^{8}$ The ideal dose of acetazolamide is not known; $0.25 \mathrm{mg}$ has been suggested, ${ }^{9}$ but this is associated with more side effects.

Each of the nine doctors and the nurse were allocated a group of clients to look after for the entire trip. Medicals were performed in Katmandu to provide a baseline for further assessments. The tests included pulse, blood pressure, chest auscultation, and neurological tests of balance including gait and Rhombergs. The athletes had constant access to doctors and were given frequent talks on the effects of altitude as they climbed. On the day before the race, an independent doctor within the team performed tests designed to assess fitness to run, especially to detect signs of altitude sickness. This involved review of the notes, supplemented by further history taking. Examination involved: auscultation of the chest and measurement of respiratory rates to detect pulmonary oedema; Rhombergs and heel to toe walking both backwards and forwards to detect cerebral oedema; auscultation of the heart and blood pressure measurement if indicated. Only after the results of these tests had been assessed as satisfactory was a race number issued and permission to ascend to the start line given. Despite these tests, one runner went on to develop symptoms of cerebral oedema as he ascended the final leg to the start line and was unable to run. Each runner's number was used as a set of notes, with current and previous problems summarised on the back, for use in the event of the runner being found unconscious during the race. It is interesting to note that pulse oximetry on the day before the race at an altitude of $4930 \mathrm{~m}(250 \mathrm{~m}$ below the starting line) showed an average oxygen saturation of $79 \%(n=25)$, with a range between $73 \%$ and $87 \%$.

On race day, there were aid and drink posts, with a doctor, every 3 miles. A backup team with a doctor swept down the course on the heels of the back markers assessing their ability to continue. Runners were given clear instructions before the race about what to do if they became exhausted or were injured and also how to react to finding another injured runner.

\section{Results}

There were 70 prospective runners with a support team of 32 people including the doctors, group leaders, marshals, organisers, and two camera crews. There were also 40 Sherpas and 50 porters.

The full marathon was completed by 63 of the 70 runners. Five runners dropped out before the race, three because of altitude sickness and one elected to stay with her tent mate who had altitude sickness. Three of these completed 17 miles of the race starting at the lower altitude of $4252 \mathrm{~m}$. One runner failed the medical as he was found to have developed atrial fibrillation associated with hypotension and was advised to descend. No other treatment was needed, and the problem was noted to have resolved three days later at $3446 \mathrm{~m}$. Two runners were stopped during the race because of exhaustion, one at 17 miles and one at 20 miles.

The failure rate of $10 \%$ is less than usual for this race, ${ }^{2}$ and underlines the challenge that the race presents.

\section{Medical problems}

Medical cards were used to provide an audit of medical problems and drug usage during the trip. Each medical consultation and doctor contact was recorded on these cards, which were held by the athletes. The cards were used in the final assessment before runners were passed fit to compete.

\section{GASTROINTESTINAL}

Gastroenteritis was extremely common, with very few people escaping entirely. Treatment was as per protocol. ${ }^{10}$ This was modified by local information from clinics in Katmandu. Fortunately antibiotic resistance is not yet a problem in Nepal. There were 65 recorded consultations: 41 were treated as bacterial, 34 being treated with ciprofloxacin and seven with ofloxacin; 17 cases of giardia were diagnosed clinically, based on watery diarrhoea and vomiting with the characteristic eggy odour, for which 15 courses of metronidazole were given and two doses of tinidazole. Imodium and buccastem were prescribed and taken often.

\section{RESPIRATORY}

Nineteen consultations were made for a cough. Six athletes were diagnosed as having chest infections and treated with amoxicillin unless allergic. The other 13 had either a cold or the "Kumbu cough". This painful and troublesome cough was originally thought to be due to laboured breathing in the cold dusty air, but has now been shown to be due to resetting of the sensitivity of the cough receptors. ${ }^{11}{ }^{12}$ It is not, however, a predictor of altitude sickness. The diagnosis of cough at altitude is notoriously difficult with a differential diagnosis of bacterial infection, viral infection, irritant cough, bronchospasm, and pulmonary oedema. We had to rely purely on clinical factors to make the diagnosis.

\section{ALTITUDE SICKNESS}

The criteria for acetazolamide prophylaxis was two or more proven episodes of altitude sickness at a level below that of the start line. Five runners fell into this category. A further runner had his second episode early in the trek and was prescribed the prophylaxis regime of $0.125 \mathrm{mg}$ twice a day from $3846 \mathrm{~m}$. It was not thought necessary for these people to ascend at a different rate from that of the main party, but they were assessed regularly above $3446 \mathrm{~m}$. With the exception of the expected side effects of increased diuresis and paraesthesia, they all remained well, except for one 65 year old veteran runner, who developed atrial fibrilla- 
Table 1 List of drugs provided for the 1999 Everest marathon

\begin{tabular}{|c|c|c|}
\hline Drug & Numbers and doses & Usage \\
\hline \multicolumn{3}{|l|}{ Eye preparations } \\
\hline Amethocaine eye drops & $0.5 \% \times 5$ & Not used \\
\hline Chloramphenicol eye drops & $0.5 \% \times 10$ & Not used \\
\hline Fluorescein eye drops & $1 \% \times 10$ & Not used \\
\hline Gentamicin eye drops & $0.3 \% \times 10$ & Not used \\
\hline Cromoglycate eye drops & $13.5 \mathrm{ml} \times 10$ & Enough \\
\hline Dexamethasone/framycetin/gramicidin eye drops & $5 \mathrm{~g} \times 20$ each & Too many \\
\hline \multicolumn{3}{|l|}{ Ear preparations } \\
\hline Hydrocortisone/neomycin/polymixin ear drops & $5 \mathrm{ml} \times 10$ & Enough \\
\hline \multicolumn{3}{|l|}{ Nose preparations } \\
\hline Beclomethasone AQ spray & 20 & Enough \\
\hline \multicolumn{3}{|l|}{ Neuro preparations } \\
\hline Sumatriptin tablets & $100 \mathrm{mg} 5 \times 350 \mathrm{mg} \times 6$ & Too many \\
\hline Diazepam rectal tubes & $10 \mathrm{mg} \times 2$ boxes of 5 & Not used \\
\hline \multicolumn{3}{|l|}{ Altitude preparations } \\
\hline Dexamethasone tablets & $500 \mathrm{mg} \times 500 / 2 \mathrm{mg} \times 500$ & Enough \\
\hline Acetazolamide tablets & $500 \times 1.25 \mathrm{~g}$ & Enough \\
\hline Prednisolone tablets & $5 \mathrm{mg} 3 \times 100$ & Enough \\
\hline \multicolumn{3}{|l|}{ Analgesics } \\
\hline Diclofenac tablets & $50 \mathrm{mg} \times 21 \times 10$ & Enough \\
\hline Codeine/aspirin tablets & 200 & Enough \\
\hline Ibuprofen tablets & $400 \mathrm{mg} \times 500$ & Enough \\
\hline Ketoprofen gel & 10 & Enough \\
\hline Diclofenac injection & $5 \times 75 \mathrm{mg}$ & Enough \\
\hline Morphine injection & $5 \times 15 \mathrm{mg} / \mathrm{ml}$ & Enough \\
\hline Mefenamic acid & $250 \mathrm{mg} \times 10$ packs & Not used \\
\hline Buprenorphine tablets & 50 & Not used \\
\hline Paracetamol & $3 \times 500$ & Too little \\
\hline Dextropropoxyphene/paracetamol & 200 & Enough \\
\hline Etodolac SR & $7 \times 30$ & Enough \\
\hline Meptazinol & $1 \times 100$ & Not used \\
\hline \multicolumn{3}{|l|}{ Antifungal preparations/skin } \\
\hline Betamethasone cream & $30 \mathrm{~g} \times 20$ & Too many \\
\hline Gentamicin cream & $30 \mathrm{~g} \times 6$ & Enough \\
\hline Benzalkonium antiseptic cream & $100 \mathrm{~g} \times 3$ packs & Not used \\
\hline Hydrocortisone/miconazole cream & 10 boxes & Enough \\
\hline Crotamiton cream and lotion & $100 \mathrm{~g} \times 12$ & Too many \\
\hline Miconazole vaginal & 10 & Not used \\
\hline Clobetasone/oxytetracycline/nystatin cream & $30 \mathrm{~g} \times 10$ & Not used \\
\hline Acyclovir cream & $10 \mathrm{~g} \times 4,2 \mathrm{~g} \times 1$ & Enough \\
\hline Acyclovir ointment & $4.5 \mathrm{~g} \times 4$ & Enough \\
\hline \multicolumn{3}{|l|}{ Anti-helminth preparations/antibiotic preparations } \\
\hline Amoxicillin capsules & $250 \mathrm{mg} 500 \times 2$ & Enough \\
\hline Ciprofloxacin tablets & $500 \mathrm{mg} \times 10$ & Too little \\
\hline Erythromycin & $500 \mathrm{mg} 56 \times 5$ packs & Too many \\
\hline Metronidazole tablets & $400 \mathrm{mg} \times 14 \times 50$ & Too little \\
\hline Flucloxacillin tablets & $500 \mathrm{mg} \times 500$ & Enough \\
\hline Idoxuridine $5 \%$ & $5 \mathrm{ml} \times 3$ packs & Too many \\
\hline Flucloxacillin/ampicillin tablets & $500 \mathrm{mg} \times 500$ & Too many \\
\hline Mebendazole tablets & 10 & Not used \\
\hline Cefuroxime injection & $1.5 \mathrm{~g} \times 20$ & Enough \\
\hline Cefuroxime tablets & $250 \mathrm{mg} 2 \times 50$ & Enough \\
\hline Ofloxacin tablets & $200 \mathrm{mg} \times 100$ & Too little \\
\hline \multicolumn{3}{|l|}{ Antihistamine preparations } \\
\hline Promethazine tablets & $25 \mathrm{mg} \times 56$ & Not used \\
\hline Chlorpheniramine tablets & $4 \mathrm{mg} \times 500$ & Enough \\
\hline Cetirizine tablets & 30 & Enough \\
\hline Sleepers & & \\
\hline Zopiclone tablets & $7.5 \mathrm{mg} \times 28$ & Not used \\
\hline Respiratory preparations & & \\
\hline Beclomethasone 200 inhaler & 20 & Not used \\
\hline Salbutamol accuhaler & 20 & Not used \\
\hline Salbutamol (inhalers) & 10 & Not used \\
\hline Salbutamol injection & $0.25 \mathrm{mg} 1 \times 10$ & Not used \\
\hline IV fluids & & \\
\hline Haemacel & $\times 3 \times 500 \mathrm{ml}$ & Enough \\
\hline $\mathrm{D} /$ Saline & $\times 6 \times 500 \mathrm{ml}$ & Enough \\
\hline Giving sets & $\times 6$ & Enough \\
\hline Gastric preparations/anti-emetic preparations & & \\
\hline Choline salicylate dental gel & 10 tubes & Not used \\
\hline Prochlorperazine buccal & Pack of $10 \times 50$ & Too little \\
\hline Cinnarizine & $15 \mathrm{mg} \times 10$ & Enough \\
\hline Alginate tablets & $20 \times 20$ & Too little \\
\hline Lozenges & 20 & Too little \\
\hline Ranitidine tablets & $150 \mathrm{mg} \times 300$ & Enough \\
\hline Metoclorpropamide tablets & $10 \mathrm{mg} / 2 \mathrm{ml} \times 12$ & Enough \\
\hline
\end{tabular}

Continued on page 208. tion at $4930 \mathrm{~m}$. It is impossible to say whether acetazolamide treatment precipitated this.

Six people were advised to descend during the acclimatisation process at altitudes above $3446 \mathrm{~m}$, in each case because of early signs of cerebral oedema such as headache and vomiting. One lady suffered acute cerebral oedema due to gross trunkal ataxia; she was treated with acetazolamide, intravenous dexamethasone, high flow oxygen, and recompression in the Gamow bag before being carried on a Sherpa's back six miles down the mountain in a snowstorm. She made a complete recovery, and two days later completed 17 miles of the race in a good time. The incidence of cerebral oedema was high, and it is difficult to explain this.

Two of the six were able to rejoin the party and start the race after sleeping at a lower altitude for one or more nights. There were 27 other consultations for altitude related problems, mainly headache. Two people received intravenous fluids, one for dehydration resulting from a severe gastric upset and one after the race for dehydration and exhaustion after running the marathon with a broken rib secondary to a severe cough.

\section{MUSCULOSKELETAL}

Seven people suffered blistering of the feet severe enough to need medical intervention. Three treatments were given for insect bites, and two ticks were removed under local anaesthetic. One ingrowing toenail was also removed. One dislocated metacarpophalangeal joint of the left thumb was relocated after a fall. Three cases of Achilles tendonitis, one trochanteric bursitis, and one semimembranous bursitis responded to treatment. A severe talocalcaneal ligament sprain responded to strapping, non-steroidal treatment, and osteopathy/ physiotherapy. A dog bite from a potentially rabid dog required helicopter evacuation, which was able to be arranged within 24 hours because of good weather and the presence of a satellite phone. Anti-rabies immunisation was begun in Katmandu and continued on the trail. Rabies prophylaxis has not been considered as a prerequisite for all competitors as it does not prevent the need for emergency evacuation for further injections. ${ }^{13}$ Cuts to the head resulted from a stone falling from a building. A severe left otitis media caused dizziness sufficient to prevent walking for 36 hours; however, this runner made up the time, and five days later won the ladies' race.

EAR, NOSE, AND THROAT

Nasal blockage and sinus pain was treated with nasal decongestants on four occasions. Rhinitis and nasal obstruction resulting from increased nasal mucociliary transport times have been documented at altitude. ${ }^{14}$

\section{Physical therapy}

The osteopath and physiotherapist provided valuable support for the doctors. The physiotherapist carried a portable ultrasound machine, which she used as in her normal practice. The osteopath treated 10 people, 
Table 1 List of drugs provided for the 1999 Everest marathon (continued)

\begin{tabular}{|c|c|c|}
\hline Drug & Numbers and doses & Usage \\
\hline \multicolumn{3}{|l|}{ Lower GI preparations } \\
\hline Beclomethasone rectal ointment & $30 \mathrm{~g} \times 20$ & Not used \\
\hline Loperamide tablets & $2 \mathrm{mg} \times 2$ packs $\times 250$ & Too little \\
\hline Co-phenotrope tablets & 200 & Enough \\
\hline Senna tablets & 50 & Too many \\
\hline \multicolumn{3}{|l|}{ Cardiac preparations } \\
\hline Nifedipine retard tablets & $60 \mathrm{mg} \times 40$ & Not used \\
\hline \multicolumn{3}{|l|}{ Miscellaneous } \\
\hline Penicillin injection (note expiry date) & $2.4 \mathrm{mu} \times 6 \mathrm{ml}(10) \times 3$ packs & Too many \\
\hline Butterflys & 6 & Not used \\
\hline Chlorhexitulle & Packs of $10 \times 2$ & Enough \\
\hline Crepe bandage & 12 & Enough \\
\hline Compressin bandage & 1 & Too little \\
\hline Decubal cream & 20 tubes of $100 \mathrm{~g}$ & Not used \\
\hline Methyl prednisolone injection & $5 \times 40 \mathrm{~g}$ & Not used \\
\hline Diazepem injection & $2 \mathrm{ml} \times 1$ box of 10 & Not used \\
\hline Hydrocortisone injection & $10 \times 2 \mathrm{ml}$ & Enough \\
\hline Ethilon sutures & 20 & Not used \\
\hline Silver sulphadiazine cream & 2 & Not used \\
\hline Gloves & 200 & Enough \\
\hline Glucagon & 3 & Not used \\
\hline Lipscreen & 42 & Enough \\
\hline Lipobase cream & $50 \mathrm{~g} \times 3$ packs & Not used \\
\hline Locoid cream & $100 \mathrm{~g} \times 3$ & Not used \\
\hline Locoid ointment & $100 \mathrm{~g} \times 3$ & Not used \\
\hline Lignocaine & $20 \times 2 \mathrm{ml} \times 1 \%$ & Enough \\
\hline Lignocaine & $30 \times 2 \mathrm{ml} \times 2 \%$ & Enough \\
\hline Medi swabs & 100 & Enough \\
\hline Micropore & Various sizes & Too little \\
\hline Hydrocortisone $1 \%$ & $30 \mathrm{~g} \times 3$ packs & Not used \\
\hline Needles & Various & Too many \\
\hline Oxygen masks \& tubes & 8 cylinders & Enough \\
\hline Plastering equipment & $\times 3$ sets & Not used \\
\hline Rehydration powders & 250 & Enough \\
\hline Povidine/iodine dry powder & $500 \mathrm{ml} \times 3 / 250 \mathrm{ml} \times 4$ & Enough \\
\hline Splints & Various & Enough \\
\hline Steri-strips & 48 & Too many \\
\hline Cannulae & 6 grey $/ 6$ green & Enough \\
\hline Suture kits & 2 & Too little \\
\hline Syringes & Various & Enough \\
\hline Sterile dressing packs & 10 & Too little \\
\hline Silicon dressings & 20 & Not used \\
\hline Tubular bandages & 6 & Enough \\
\hline Vaginal speculae & 4 & Not used \\
\hline
\end{tabular}

The drug list has evolved over the 12 years of the running of the Everest marathon. It is very similar to other recommended lists for high altitude expeditions. ${ }^{15}{ }^{16}$

averaging 2.3 consultations per person. The physiotherapist treated nine people, averaging 1.8 consultations per person. Both were particularly useful in dealing with non-life threatening but troublesome musculoskeletal problems as outlined above.

\section{Illness outside the party}

The doctors were often asked to treat Sherpas, porters, and local Nepalese people. This was usually uneventful. We tried to avoid treating local people to discourage dependency on tourists and undermining local health care provision, and only offered advice on emergencies. We were asked to help a young man who had been the victim of a machete attack. His injuries included severe lacerations to the head, arms, and trunk. Although conscious, he was shocked and required resuscitation with intravenous fluids and antibiotics. General anaesthesia with ketamine was performed to enable cleaning and dressing of his wounds; he was then dispatched to the nearest medical centre. The anaesthesia was performed on open ground by the path at $3000 \mathrm{~m}$.

\section{Drug usage}

The drugs were raised without a budget, which was a long and difficult begging job for the chief medical officer. Table 1 shows the drugs taken. Quinolone antibiotics were the only drugs underestimated. This resulted from a change in the protocol for treating gastroenteritis on advice from local doctors. The need to carry intravenous fluids and full anaesthetic equipment was demonstrated, as were the life saving benefits of the Gamow bag and oxygen. Table 1 shows whether the quantity of drug taken was considered too much, enough, or too little, or whether it was not used at all. It is hoped that this can be used to plan the medical provisions for further expeditions.

\section{Discussion}

The remoteness of the Everest marathon, the length of time spent away from medical aid, the cold, altitude, and seriousness of the terrain combine to make it arguably the toughest marathon in the world. Provision of medical aid is hampered by the need to carry everything on the backs of porters or Sherpas. The extremes of temperature and the lack of electrical sources to recharge batteries make difficult the use of machines taken for granted elsewhere. For example, ultrasound machines need to be selected for versatility and durability. The need for the presence of a doctor every 3 miles and one in a backup team during the race means a minimum team of 10 . The need to deal with every eventuality suggests that the mix of skills among the doctors should be varied and all encompassing. Knowledge of sports injuries, sports psychology, and altitude medicine is recommended.

It is interesting to look at how the easy availability of medical advice affects the incidence of illness noted among the participants. The athletes have invested a lot of time and money in attempting to complete the marathon, and, as the race approaches and they are travelling up into the cold thin air of Everest base camp, they experience changes that they fear may stop them from running. It is crucial for the medical team to have clear and uniform guidelines to avoid giving the athletes multiple and conflicting advice. Protocols clearly help here.

The high incidence of diagnosis of altitude sickness, with subsequent descent, is interesting. Certainly, we doctors were careful in our assessments and played safe. We also had the medical manpower and Sherpa back up to arrange different rates of ascent for casualties, which is beyond the capabilities of smaller trekking groups. We witnessed groups alongside us that were without medical supervision in which many sicker people were allowed to remain at altitude or indeed ascend. People die each year in the Himalayas from altitude sickness, usually because the signs have been ignored or rationalised to be less severe than they are. Our expedition was also unique in that the participants were not just aiming to get to base camp but were going to spend a night there and then run a marathon the following day. These factors may explain the high pick up and treatment rate of early altitude sickness. I believe the lack of serious morbidity or mortality justifies the cautious approach.

Many drugs were carried that were not used. Although this represented heavy carrying work 
for the porters, the athletes had the expectation of a "pill for every ill" and were disappointed that unlimited supplies of throat lozenges and cough linctus, for example, were not available. The unused drugs were all donated to local hospitals. The anaesthetic kit, 10 cylinders of oxygen, intravenous fluids, and the portable recompression chamber were all used and should be taken on all subsequent trips. The life saving potential of the recompression chamber was demonstrated and is recommended for anyone travelling above $4000 \mathrm{~m}$.

Finally, education of the athletes, before and during the trek, about adequate hydration, personal hygiene, and effects of altitude helped them to distinguish the normal from the abnormal and encouraged them to seek medical advice sensibly.

1 Peacock A. Oxygen at high altitude, clinical review. BMf 1998;317:1063-6.

2 Sherpani DP. The Everest marathon; the story of the world's highest marathon. Kendal: Titus Wilson and Son, 1988.
3 Sherpani DP. Everest marathon, 1987-1999. Bowness on Windermere, Cumbria: Badger Press, 1999.

4 Buckler D. Three miles high and one hundred miles from the nearest road. Br $\mathcal{F}$ Sports Med 1998;32:262-3.

5 Bezruchka, S. Altitude illness; prevention and treatment. Leicester: Cordee Publishers, 1994:27.

6 Illingworth R. Medical equipment for expeditions. BMF $1981 ; 282: 202-5$

7 Stoneham MD. Anaesthesia and resuscitation at altitude. Eur F Anaesthesiol 1995;12:249-57.

8 High altitude medicine guide. Katmandu: Himalayan Rescue Association.

9 Coote JH. Medicine and mechanisms in altitude sickness; review article. Sports Med 1995;20:148-59.

10 Caeiro JP, DuPont HL. Management of traveler's diarrhoea Caeiro JP, DuPont HL. Manager
[review]. Drugs 1998;56:73-81.

11 Barry PW, Mason NP, Riordan M, et al. Cough frequency and cough receptor sensitivity are increased in man at altitude. Clin Sci 1997;93:181-6.

12 Mason NP, Barry PW, Despian G, et al. Cough frequency and cough receptor sensitivity to citric acid challenge during a simulated ascent to extreme altitude. Eur Respir $\mathcal{F}$ 1999;13:508-13.

13 British National Formulary. London: BMA/Royal Pharmaceutical Society, BMA Publishing.

14 Barry PW, Mason NP, O’Callaghan C. Nasal mucociliary transport is impaired at altitude. Eur Respir $\mathcal{F}$ 1997;10:35tran

15 Pollard A, Murdoch D. The high altitude medicine textbook. 2nd ed. Oxford: Radcliffe Medical Press, 1998.

16 A'Court CHD, Stables RH, Travis S. Doctor on a mountaineering expedition. BMF 1995;310:1248-52.

\section{Take home message}

Sporting events in the most extreme of places and conditions can safely take place provided adequate medical facilities and resources are available, along with adequate education of the participants. 